\title{
A mixed malaria infection: is Plasmodium vivax good for you?
}

J. Whitehorn ${ }^{1,2, *}$, C. Coltart ${ }^{1}$, D. Manser ${ }^{1}$, T. Doherty $^{1,2}$

${ }^{1}$ Hospital for Tropical Diseases, University College Hospitals NHS Trust, London, UK

2 London School of Hygiene and Tropical Medicine, London, UK

* Corresponding author. Present address: Hospital for Tropical Diseases, Mortimer Market Centre, Capper Street, London WC1E 6JB, UK. Tel.: +44 8451555000.

E-mail address: james.whitehorn@uclh.nhs.uk (J. Whitehorn). 
Summary We describe a case of mixed malaria infection in a returning traveller. We suggest that our patient had a chronic infection with Plasmodium vivax and that this reduced the severity of an acute infection with $P$. falciparum - an example of crossspecies immunity.

KEYWORDS Malaria; Immunity; Plasmodium falciparum; Plasmodium vivax 


\section{Introduction}

Malaria is a common diagnosis in returning travellers $;{ }^{1}$ mixed malaria infections are seen less frequently. We report a case of a mixed malaria infection, and suggest that infection with one species may reduce the severity of the other infection.

\section{Case report}

A 25-year-old white man presented to the emergency clinic of the Hospital for Tropical Diseases, London, UK on 8 September 2008, shortly after returning from leading a 5 month expedition in Papua New Guinea. His symptoms began with a single episode of diarrhoea, which was followed by a 6 day history of dry cough, fever and sweats. While in Papua New Guinea he trekked in the jungle, and slept in hammocks under a mosquito net. He was not fully compliant with his malaria chemoprophylaxis, and took doxycycline only intermittently. Of note, before this expedition, he had lived in rural Tanzania for 2 years working on conservation projects, but was well during this period.

On examination, he was pyrexial at $40.8^{\circ} \mathrm{C}$, but appeared well. Physical examination was unremarkable apart from pallor. Blood tests showed haemoglobin $7.7 \mathrm{~g}$ and platelets $48 \times 10^{9} / \mathrm{l}$; renal function was normal. A thin film demonstrated trophozoites and schizonts of Plasmodium falciparum, with $0.2 \%$ parasitaemia. In addition, all stages of $P$. vivax were seen (Figure 1).

He was initially treated with oral quinine, $700 \mathrm{mg}$ three times daily, followed by a stat dose of Fansidar (sulfadoxine-pyrimethamine; three $500 \mathrm{mg} / 25 \mathrm{mg}$ tablets). His glucose-6-phosphate dehydrogenase levels were normal, and thus a 2 week course Fansidar at the start of quinine treatment? of primaquine $15 \mathrm{mg}$ twice daily was prescribed. His parasitaemia cleared during his 
admission, and by the fourth day only gametocytes of each species could be seen. On discharge, he was given a 1 month course of ferrous sulphate and folic acid in view of his anaemia. He made a full recovery.

\section{Discussion}

Immunity to malaria in humans is poorly understood, but is thought to be both species- and genotype- (within a species subclass) specific. It has been reported that in mixed infections in humans, cross-species or cross-genome interaction exists between malaria parasites. ${ }^{2} \mathrm{~A}$ reduction in the severity of malaria symptoms occurs in individuals pre-exposed to different species, ${ }^{3}$ and Plasmodium vivax infection may protect against the severe complications of $P$. falciparum. ${ }^{2,4}$ This effect is thought partially to explain the lower mortality rates from $P$. falciparum seen in the AsiaPacific region compared with Africa. ${ }^{5} \mathrm{~A}$ recent study has shown that sera from a volunteer experimentally infected with $P$. vivax suppressed the growth of $P$. falciparum in vitro. ${ }^{6}$ This effect was mediated via lgM antibodies, and could be the means by which $P$. vivax infection protects against $P$. falciparum.

We propose that this case represents an example of cross-species protection.

Patients with $P$. falciparum schizonts in their peripheral blood film are often extremely unwell, but this was not the case in our patient. In addition, his marked anaemia suggests that he had a chronic malaria infection, most likely with $P$. vivax, and an acute secondary infection, probably with $P$. falciparum, that precipitated the symptoms leading to admission. Although his intermittent chemoprophylaxis may have played a role, it is probable that a chronic dual infection was responsible for the suppression of the severe manifestations of disease in this case. 
Authors' contributions: All the authors were involved in the management of the case; JW, CC and TD prepared the manuscript; DM processed the blood film and produced the picture. All authors read and approved the final manuscript. JW and TD are guarantors of the paper.

Funding: None.

Conflicts of interest: None declared.

Ethical approval: Not required. The patient gave informed consent for this case report to be written. The patient's assessment and treatment were in accordance with standard UK clinical practice. 


\section{References}

1. Lalloo DG, Shingadia D, Pasvol G, Chiodini PL, Whitty CJ, Beeching NJ, et al. UK malaria treatment guidelines. J Infect 2007;54:111-21.

2. Bruce MC, Donnelly CA, Alpers MP, Galinski MR, Barnwell JW, Walliker D, et al. Cross-species interactions between malaria parasites in humans. Science $2000 ; 287: 845-8$.

3. Gunewardena DM, Carter R, Mendis KN. Patterns of acquired anti-malarial immunity in Sri Lanka. Mem Inst Oswaldo Cruz 1994;89:63-5.

4. Maitland K, Williams TN, Bennett S, Newbold CI, Peto TE, Viji J, et al. The interaction between Plasmodium falciparum and $P$. vivax in children on Espiritu Santo Island, Vanuatu. Trans R Soc Trop Med Hyg 1996;90:614-20.

5. Alles HK, Mendis KN, Carter R. Malaria mortality rates in South Asia and in Africa: implications for malaria control. Parasitol Today 1998;14:369-75.

6. Nagao Y, Kimura-Sato M, Chavalitshewinkoon-Petmitr P, Thongrungkiat S, Wilairatana $\mathrm{P}$, Ishida $\mathrm{T}$, et al. Suppression of Plasmodium falciparum by serum collected from a case of Plasmodium vivax infection. Malar J 2008;7:113. 


\section{[Figure legend]}

Figure 1 Giemsa-stained blood film showing an early trophozoite of Plasmodium falciparum (A) and a late trophozoite of $P$. vivax (B). 